Check for updates

Cite this: Phys. Chem. Chem. Phys., 2018, 20, 9281

Received 16th November 2017, Accepted 5th February 2018

DOI: $10.1039 / c 7 c p 07747 e$

rsc.li/pccp

\section{From small molecules to polymeric catalysts in the oscillatory carbonylation reaction: multiple effects of adding $\mathrm{HI} \dagger$}

\begin{abstract}
Anna Isakova, (D)*a Billy J. Murdoch ${ }^{\mathrm{b}}$ and Katarina Novakovic ${ }^{\mathrm{a}}$
The oscillatory palladium-catalysed carbonylation reaction opens new horizons for applications in smart materials due to the versatility of its conditions and substrates, as well as the adjustability of amplitude and period of $\mathrm{pH}$ oscillations. A variety of viable substrates have been demonstrated, including polymeric alkyneterminated substrates. However, so far, there have not been any reports of polymer-based palladium catalysts in oscillatory mode. In this paper, we demonstrate $\mathrm{pH}$ oscillations in various systems, using commercially available palladium acetate, a triphenylphosphine palladium acetate complex and a polymer-bound palladium catalyst. While palladium acetate was able to generate oscillations under the conditions already established in our previous research on $\mathrm{Pdl}_{2}$-catalysed oscillators, the other two catalysts needed the addition of $\mathrm{HI}$ to induce oscillations. $\mathrm{HI}$ forced an initial $\mathrm{pH}$ drop, bringing $\mathrm{pH}$ into the range where oscillations generally occur. Addition of $\mathrm{HI}$ had a significant effect on all catalysts, modifying the amplitude and period of oscillations, oscillation mode, as well as starting material conversion and product distribution.
\end{abstract}

\section{Introduction}

Oscillatory chemical reactions have been known for decades. ${ }^{1}$ Currently these reaction systems are generating profound interest in materials science as a driving force for smart materials, owing to the ability of smart materials to sense and react to changes in the environment, generated during the oscillatory process. $^{2}$ A number of self-oscillating materials and architectures have been reported, based on such reactions as the Landolt clock or Belousov-Zhabotinsky reaction. ${ }^{3-5}$

The palladium-catalysed oxidative carbonylation (PCOC) reaction has recently attracted attention due to its ability to exhibit oscillations in $\mathrm{pH}$, redox potential, turbidity and heat of reaction. ${ }^{6-8}$ The most studied system employs phenylacetylene (PhAc) as substrate due to the facile analysis of products ${ }^{9}$ and uses $\mathrm{PdI}_{2}$ as a catalyst. Oscillations in the $\mathrm{PhAc} / \mathrm{PdI}_{2}$ system are sustained in a batch reactor for days of monitoring with the possibility of varying the amplitude and period of oscillations by adjusting the temperature of reaction, ${ }^{10,11}$ concentration of the catalyst, substrate or even water content. ${ }^{12,13}$ Besides the sustained oscillations, the PCOC reaction has demonstrated a temperature-dependent product selectivity, which is potentially

\footnotetext{
${ }^{a}$ School of Engineering, Newcastle University, Newcastle upon Tyne, NE1 7RU, UK. E-mail: anna.isakova@newcastle.ac.uk

${ }^{b}$ National EPSRC XPS Users' Service (NEXUS), School of Engineering,

Newcastle University, Newcastle upon Tyne, NE1 7RU, UK

$\dagger$ Electronic supplementary information (ESI) available. See DOI: 10.1039/c7cp07747e
}

useful for industrial application due to a reduction of costs for isolation and purification, ${ }^{14}$ applicable to a number of substrates, as demonstrated by Gorodsky. ${ }^{15-17}$ Recently oscillations in $\mathrm{pH}$ were reported for PCOC, where an alkyne-functionalised polymeric substrate (poly(ethylene glycol)methyl ether acetylene, abbreviated as PEGA) was employed in place of PhAc, extending the opportunities of application of PCOC in smart materials. ${ }^{13}$

Although the PCOC reaction in oscillatory mode has been studied in depth by Novakovic et al., Gorodsky and Temkin et al., the evidence for other palladium catalysts' activity displaying similar dynamics in this reaction system is lacking. While studies of similar carbonylation reactions have demonstrated the application of palladium diacetate ${ }^{18}$ and palladium chloride, ${ }^{19}$ no oscillations were reported. In this work, we studied a number of commerciallyavailable palladium catalysts for application in PCOC (Fig. 1), in order to explore their potential for oscillatory dynamics that could lead to future applications in smart materials as part of more complex architectures. By studying the catalyst on three levels from small molecule through a ligand-metal complex to a polymersupported ligand-metal complex - we obtained a better insight into the working boundaries of the reaction.

\section{Experimental part}

\section{Materials}

Materials studied were used as received: palladium acetate (PdAc), bis(acetato)bis(triphenylphosphine)palladium(II) (L-Cat), 
<smiles>CO[Ga]OC(C)=O</smiles>

PdAc

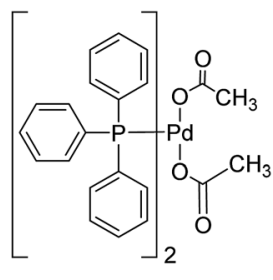

L-Cat

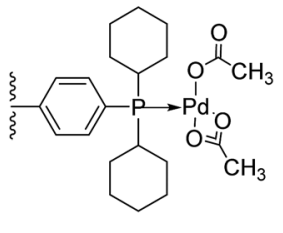

P-Cat
Fig. 1 Structures of the studied catalysts with their notations.

di(acetato)dicyclohexylphenylphosphinepalladium(II), polymerbound FibreCat ${ }^{\mathbb{R}}$ (Pd 5\%, extent of labeling: 0.4-0.6 $\mathrm{mmol} \mathrm{g}^{-1}$ $\mathrm{PPH}_{3}$ ligand content loading, P-Cat), palladium(II) iodide ( $\geq 99.99 \%$ trace metals basis), hydroiodic acid (HI, $\geq 57 \%$ ), phenylacetylene (PhAc, 98\%), triphenylphosphine ( $\geq 95.0 \% \mathrm{GC}$ ), methanol (HPLC Plus, $\geq 99.9$ ) all Sigma Aldrich; naphthalene (extra pure), potassium iodide $\left(\geq 99 \%\right.$ GPR RECTAPUR $\left.{ }^{\mathbb{R}}\right)$, VWR Chemicals; buffer solutions: $\mathrm{pH} 2.00$ (glycine), $\mathrm{pH} 7$ (phosphate) and $\mathrm{pH} 10$ (borate) (all NIST Standard, ready to use for $\mathrm{pH}$ measurement, Fisher Chemical). Pure air and carbon monoxide were supplied by BOC. $\mathrm{Na}_{2} \mathrm{PdAc}_{2} \mathrm{Cl}_{2}$ was synthesised by mixing 2 equiv. of $\mathrm{NaCl}$ with 1 equiv. of PdAc in methanol for $18 \mathrm{~h}$.

\section{The reaction}

The reaction was performed in a flat-bottom Erlenmeyer flask $(100 \mathrm{ml})$ at constant stirring, using the HEL Micronote system to record $\mathrm{pH}$ and temperature within the bulk of the reaction. Prior to the reaction, probes were calibrated at room temperature $\left(17-20^{\circ} \mathrm{C}\right)$ against buffer solutions of $\mathrm{pH} 2,7$ and 10 . The stated amounts of KI ( $4.150 \mathrm{~g}, 25 \mathrm{mmol})$, catalyst ( $30 \mathrm{mg}$ PdAc, $98.5 \mathrm{mg}$ L-Cat or $285 \mathrm{mg}$ P-Cat) and naphthalene $(256 \mathrm{mg}$, used as an internal standard for subsequent GC-MS analysis) were all charged into the flask and dissolved (or suspended for P-Cat) in $100 \mathrm{ml}$ HPLC grade methanol. The $\mathrm{pH}$ monitoring was initiated while the solids were dissolving with the stabilisation of $\mathrm{pH}$ taken as indication of complete dissolution of KI. At that point, purging through the solution with $\mathrm{CO}\left(15 \mathrm{ml} \mathrm{min}^{-1}\right)$ and air $\left(15 \mathrm{ml} \mathrm{min}^{-1}\right.$ ) commenced. After 10-20 min (or after stabilisation of $\mathrm{pH}$ following an initial drop), phenylacetylene $(1.38 \mathrm{ml}$, $12.57 \mathrm{mmol}$ ) was added. The system was monitored continuously for changes in $\mathrm{pH}$ and temperature of the reaction. It should be noted that the $\mathrm{pH}$ electrode was calibrated against aqueous buffer solutions while reaction $\mathrm{pH}$ was recorded in methanol solution. As the standard $\mathrm{pH}$ scale is based on measurements in water, $\mathrm{pH}$ values recorded in non-aqueous solutions need to be adjusted prior to being converted to hydrogen ion concentrations. It has been reported that in $100 \%$ methanol, $\mathrm{pH}$ values can be adjusted by adding 2.3 to the observed $\mathrm{pH}$ measurements to get the equivalent $\mathrm{pH}$ value in water. ${ }^{20}$ As the focus of this paper is comparison of the oscillatory trend achieved in $\mathrm{pH}$, it was not needed to adjust $\mathrm{pH}$ values since the trend remains the same in both recorded and adjusted $\mathrm{pH}$ values. A detailed study of the effect a methanol-water solvent composition has on recorded $\mathrm{pH}$ and actual concentration of acid present in solution has been previously published for the $\mathrm{PdI}_{2} / \mathrm{PhAc}$ oscillatory carbonylation system. ${ }^{12}$
Samples were taken at the end of the experimental runs (unless otherwise stated within the main text) and filtered over silica prior to being diluted 1:2 with methanol. The samples were analysed for starting material conversion and product distribution by a Varian Saturn 2200 gas chromatograph fitted with a VF-5ms column $(30 \mathrm{~m})$ and equipped with a mass spectrometry detector (GC-MS). The method was as follows: injector temperature $150{ }^{\circ} \mathrm{C}$; helium flow rate $1 \mathrm{ml} \mathrm{min}^{-1}$; oven temperature $100-195{ }^{\circ} \mathrm{C}$ over $35 \mathrm{~min}$ in 5 steps.

\section{X-ray photoelectron spectroscopy (XPS)}

X-ray photoelectron spectroscopy (XPS) was performed on solid catalysts in a Thermo Scientific K-Alpha spectrometer, using a monochromated Al K-Alpha source (1486 eV). The flood gun was used for charge compensation.

\section{Absorbance}

Absorbance was measured using a FLUOStar Omega microplate reader using a multiwell plate $(200 \mu \mathrm{l})$ in a wavelength range from 275 to $700 \mathrm{~nm}$ with a resolution of $1 \mathrm{~nm}$. Samples $(1 \mathrm{ml})$ were withdrawn at certain time points throughout the experiment as stated within the main text and diluted $1: 2$ with HPLC grade methanol.

\section{Results and discussion}

\section{Single mode oscillations in PdAc}

Three commercially available palladium catalysts were studied: small molecule palladium diacetate salt (denoted as PdAc), triphenylphosphine ligand palladium acetate (L-Cat) and a polymer-bound P-Cat (Fig. 1). PdAc and L-Cat are soluble in saturated KI solution in methanol, whereas polymer-bound palladium catalyst P-Cat is crosslinked and insoluble, thus providing an insight into the possibility of heterogeneous catalysis in the PCOC reaction. The changes in $\mathrm{pH}$ were monitored for 4000 min during which the reaction demonstrated oscillations (using PdAc) or stable values of $\mathrm{pH}$ (using L-Cat and P-Cat), Fig. 2.

It can be observed from Fig. 2a that palladium acetate catalysis proceeded as has generally been reported for the $\mathrm{PdI}_{2}$ catalysed systems in oscillatory mode. ${ }^{10,14}$ When the system was purged with $\mathrm{CO} / \mathrm{air}$, an initial drop in $\mathrm{pH}$ from 7.9 to 6.4 was observed, indicating the incorporation of $\mathrm{CO}$ and methanol molecules into the structure of the catalyst with a corresponding release of $\mathrm{H}^{+}$ions (Scheme 1a). ${ }^{14,21,22}$ Previous studies by other groups have suggested conversion of $\mathrm{Pd}^{2+}$ into $\mathrm{Pd}^{+}$species at this initial stage of the reaction, however, the evidence for $\mathrm{Pd}^{+}$species was not solid. ${ }^{6,23} \mathrm{~A}$ further $\mathrm{pH}$ drop from 6.4 to 3.8 occurred upon addition of the substrate and indicated the initial substrate conversion according to the generally accepted reaction mechanism. ${ }^{14}$

While general features are similar to those when using $\mathrm{PdI}_{2}$ as catalyst, previously investigated by our group, the oscillations in the PdAc system started significantly earlier, after $180 \mathrm{~min}$ (compared to well over $1000 \mathrm{~min}$ for $\mathrm{PdI}_{2}$ ). ${ }^{10}$ The reaction system employing PdAc catalyst exhibited a faster $\mathrm{pH}$ drop after 

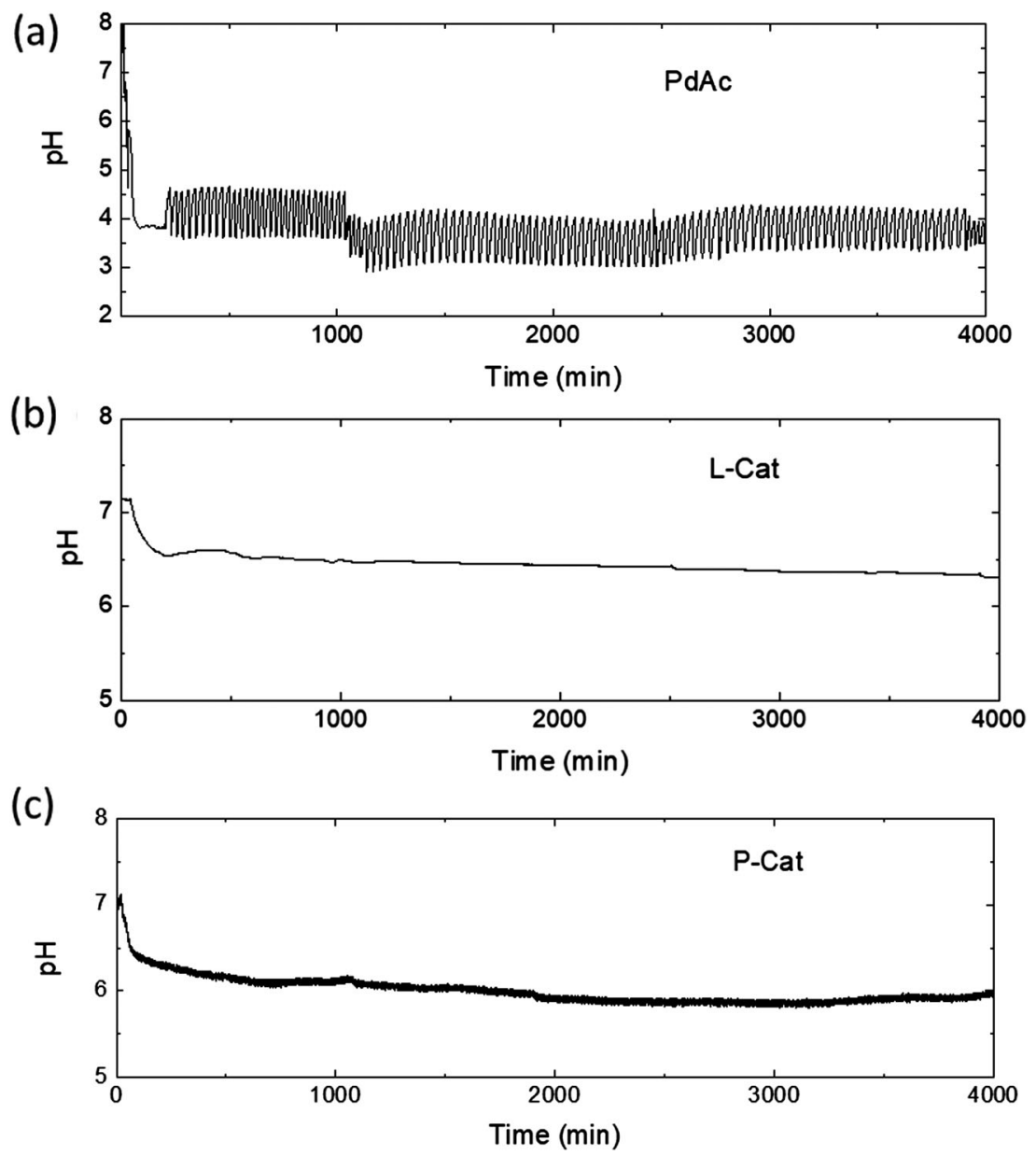

Fig. $2 \mathrm{pH}$ recorded in PCOC of phenylacetylene in methanol using various species of Pd-based catalysts at room temperature, with CO and air $\left(15 \mathrm{ml} \mathrm{min}{ }^{-1}\right.$ each): (a) PdAc; (b) L-Cat; (c) heterogeneous polymeric P-Cat.

addition of phenylacetylene with $\mathrm{pH}$ oscillations occurring shortly after. The period of oscillations for the PdAc catalyst was also shorter than when $\mathrm{PdI}_{2}$ was used (32 min and 60-70 min, respectively). This may be associated with the concentration difference $\left(1.336 \times 10^{-3} \mathrm{M}\right.$ of PdAc against $2.644 \times 10^{-3} \mathrm{M}$ $\mathrm{PdI}_{2}$ used in a previous study). When PdAc was used at a higher concentration of $2.644 \times 10^{-3} \mathrm{M}$, similar to that of $\mathrm{PdI}_{2}$ reported previously, the oscillations started even earlier (104 min) but severe clogging of gas lines occurred which disrupted the oscillations (see ESI, $†$ Fig. S1). The much shorter induction period with PdAc compared to $\mathrm{PdI}_{2}$ is most likely associated with the higher solubility of PdAc in KI solution.

Furthermore, the pattern of $\mathrm{pH}$ oscillations was different from that generally observed in $\mathrm{PdI}_{2}$ systems. $\mathrm{pH}$ oscillations in the PdAc reaction were highly regular with an amplitude of 0.98 $( \pm 0.09) \mathrm{pH}$ units and a period of $31( \pm 4) \mathrm{min}$. This regularity is frequently seen in oscillatory redox systems in a continuousflow stirred tank reactor (CSTR), ${ }^{24-27}$ but rarely observed in a batch reactor. The variations in amplitude, associated with substrate consumption and solvent evaporation, are not observed for the PdAc run, indicating the very slow conversion of substrate to products and making it one of the most stable batch oscillators reported to continue for more than $4000 \mathrm{~min}$ in the same mode. The unchanged mode of $\mathrm{pH}$ oscillations also indicates that a single oscillator is responsible for the recorded pattern. ${ }^{25}$

On the other hand, the PdAc-based catalysts L-Cat and P-Cat exhibited no oscillations. A much smaller $\mathrm{pH}$ drop occurred upon $\mathrm{CO} /$ air purging (from 7.1 to 6.9), and after the addition of substrate, $\mathrm{pH}$ decreased gradually to 6.5 and 6.1, respectively, where it plateaued (Fig. 2b and c). A ligand exchange model was proposed for all three catalysts (PdAc, L-Cat and P-Cat) to suggest how the ligands affected the initial change of $\mathrm{pH}$ during CO and air purging (Scheme 1).

Absorbance measurements of the reaction mixtures employing different catalysts were performed (see ESI, $\uparrow$ Fig. S2). When PdAc was used, absorbance measurements detected the $\mathrm{I}_{3}{ }^{-}$(generated from $\mathrm{I}_{2}$ and $\mathrm{I}^{-}$) species upon incorporation of $\mathrm{CO}$ into the catalyst, which demonstrates that $\mathrm{I}^{-}$was released, in agreement with our tentative scheme. Furthermore, the oscillatory behaviour in $\mathrm{pH}$ when PdAc was used was accompanied by oscillatory changes in the concentrations of the $\mathrm{Pd}^{2+}$ and $\mathrm{I}_{3}{ }^{-}$species. Within one oscillation, during the $\mathrm{pH}$ rise the species $\mathrm{Pd}^{2+}$ and $\mathrm{I}_{2}$ were mostly observed, while during the $\mathrm{pH}$ drop, the $\mathrm{Pd}^{2+}$ peak absorbance decreased and the $\mathrm{I}_{3}{ }^{-}$peak was predominantly observed. 
(a)

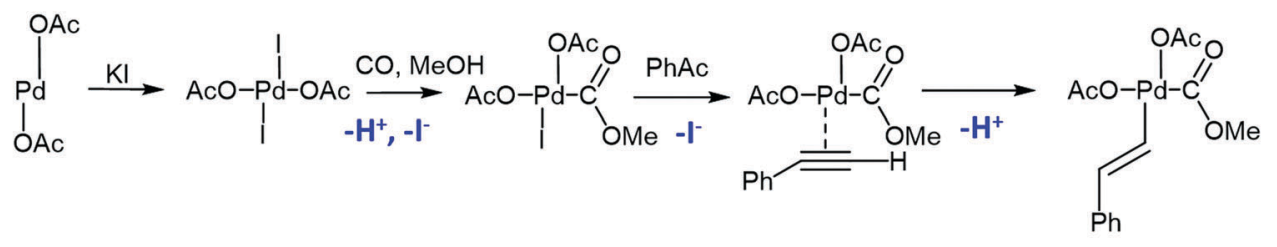

(b)

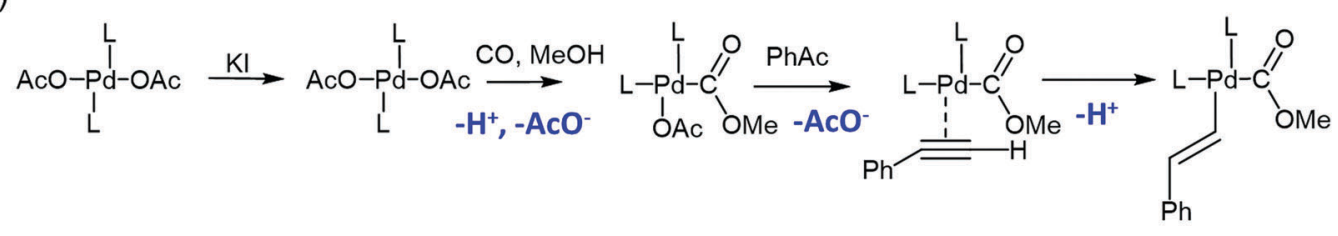

(c)

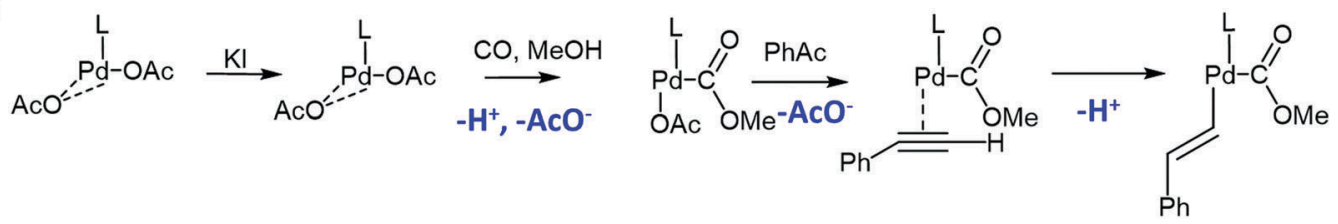

Scheme 1 Tentative model of ligand exchange proposed for PdAc, L-Cat and P-Cat. Resulting complexes participate further in the reaction to generate di-esters or are released as mono-ester by-products.

Also, not detectable by UV-Vis but visible to the naked eye, particles of metallic palladium were present during the $\mathrm{pH}$ drop. Absorbance measurements of the other two catalysts, however, demonstrated that incorporation of $\mathrm{CO}$ into the catalyst did not result in the formation of $\mathrm{I}_{3}{ }^{-}$, in agreement with Scheme 1 .

\section{Mixed-mode oscillations after addition of $\mathrm{HI}$}

For phosphine-bound Pd catalysts (L-Cat and P-Cat), pH did not reach the values where oscillations typically occurred in previous oscillatory carbonylation reactions. ${ }^{7,10,13,17}$ Therefore, three catalysts were examined further in a new set of experiments where $\mathrm{pH}$ was artificially decreased by the addition of $\mathrm{HI}$ after the addition of substrate (Fig. 3). Although when PdAc was used, addition of HI was not needed for oscillations to start, PdAc was included in this study for comparison.

PdAc exhibited delayed oscillations (Fig. 3a), when compared to the same catalyst without external addition of HI (Fig. 2a). The first series of oscillations with a relatively small amplitude and a period of 20-30 min were observed after $1200 \mathrm{~min}$, which then developed into a series of oscillations with continuously increasing amplitude. The maximum observed amplitude was $1.91 \mathrm{pH}$. This time the pattern of oscillations was irregular and complex, reminiscent of previously observed mixedmode oscillations, particularly so-called 'bursting' oscillations. ${ }^{28}$ Similar complex oscillations have been reported previously for the oscillatory Briggs-Rauscher reaction in a batch set-up. ${ }^{29}$ In that system, intermittent-bursting oscillations were characterised by the number of oscillations per burst, the duration of periods of bursts as well as the periods of gaps between them. Due to the constant change in concentration of reactant per $\mathrm{s}$ in a batch set-up, a CSTR is considered to be better suited for studying complex oscillatory behaviour. ${ }^{30}$ The complex trends in oscillatory patterns are associated with the existence of two qualitatively different behaviours replacing one another during the course of the reaction, even when all the control parameters remain the same. ${ }^{29}$ In such systems, the reaction networks (subnetworks) responsible for occurrence of small and large amplitude oscillations alternate. ${ }^{31}$ While our system was a batch reaction, observed oscillations (Fig. 3a) appeared to consist of two overlaid patterns, one with a short period of 20-30 min and another larger period of 140-290 min.

The heterogeneous polymeric P-Cat demonstrated oscillations after a long induction period of approximately $4000 \mathrm{~min}$ with the development of a similar, complex oscillatory pattern with progressively increasing amplitude and period (Fig. 3c). The large period took over 330-348 min, whereas the shorter period was of 20-53 min.

Catalyst L-Cat did not exhibit oscillations after addition of $\mathrm{HI}$ (Fig. 3b), although pH gradually decreased over the course of reaction from 6.9 to 3.8 , where oscillations were generally observed. The expected rapid large drop of $\mathrm{pH}$ when $\mathrm{HI}$ was added did not occur. This was associated with an immediate consumption of protons by the triphenylphosphine ligands of the complex (see test runs in Fig. S3, ESI $\dagger$ ), caused by their reversible dissociation. Increasing the amount of added hydroiodic acid ten-fold saw a more pronounced initial $\mathrm{pH}$ drop, similar to the other catalysts and the subsequent development of $\mathrm{pH}$ oscillations. The increase in added HI compensated for the HI consumed by the triphenylphosphine ligands during their dissociation. The oscillations in $\mathrm{pH}$ in this instance appeared after an induction period of approximately $4180 \mathrm{~min}$ (similar to the induction time using the P-Cat catalyst after the addition of HI (Fig. 3c), Fig. 4), during which the pH slowly rose from 2 to 2.8. The oscillations had a short period of 10-15 $\mathrm{min}$ and a 


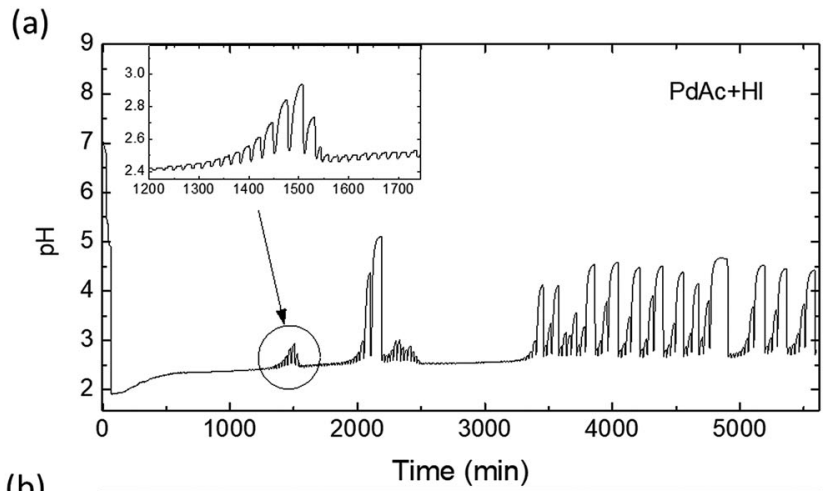

(b)

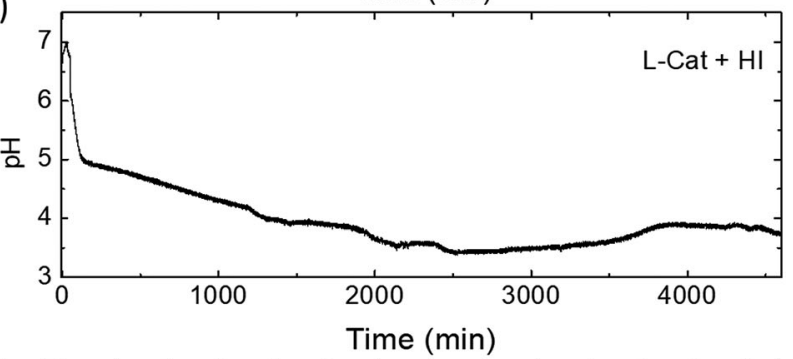

(c)

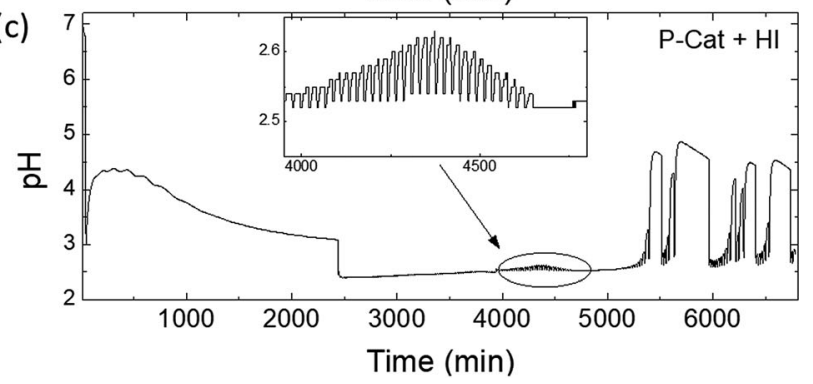

Fig. $3 \mathrm{pH}$ recorded in the PCOC of phenylacetylene in methanol using various species of Pd-based catalysts, using CO/air (each $15 \mathrm{ml} \mathrm{min}{ }^{-1}$ ) at room temperature. Following the addition of substrate (PhAc), $0.0228 \mathrm{mmol}$ HI was added.

small amplitude of $0.10-0.15$ units until the pH started rising after $9200 \mathrm{~min}$ and the amplitude increased to 0.5 units.

\section{The origin of mixed-mode oscillations}

Mixed-mode oscillations in $\mathrm{pH}$ have been observed and explained before in other systems, ${ }^{26,30,32}$ however, due to the general complexity of the PCOC mechanism (which is not $100 \%$ established), it is difficult to confidently assign the mixed-mode oscillations in PdAc and P-Cat after addition of $\mathrm{HI}$ to certain reaction networks, especially since they are also observed in certain conditions (at 10 and $20{ }^{\circ} \mathrm{C}$ ), when $\mathrm{PdI}_{2}$ is used without any $\mathrm{HI}$ addition. Thus, further studies, including the transition to a CSTR reaction set-up, are needed to clarify the underlying mechanisms of the mixed-mode patterns.

To expose the effect of two simultaneous processes with differing catalysis rates on the resulting oscillatory patterns, $\mathrm{Na}_{2} \mathrm{PdAc}_{2} \mathrm{Cl}_{2}$ catalyst was employed in place of PdAc in an otherwise identical experimental setup to that used in the experiment shown in Fig. 2a (no HI added, same concentrations of $\mathrm{KI}$, PhAc substrate and gas purging rates of $\left.15 \mathrm{ml} \mathrm{min}{ }^{-1}\right) . \mathrm{Na}_{2} \mathrm{PdAc}_{2} \mathrm{Cl}_{2}$ was selected since in saturated $\mathrm{KI}$

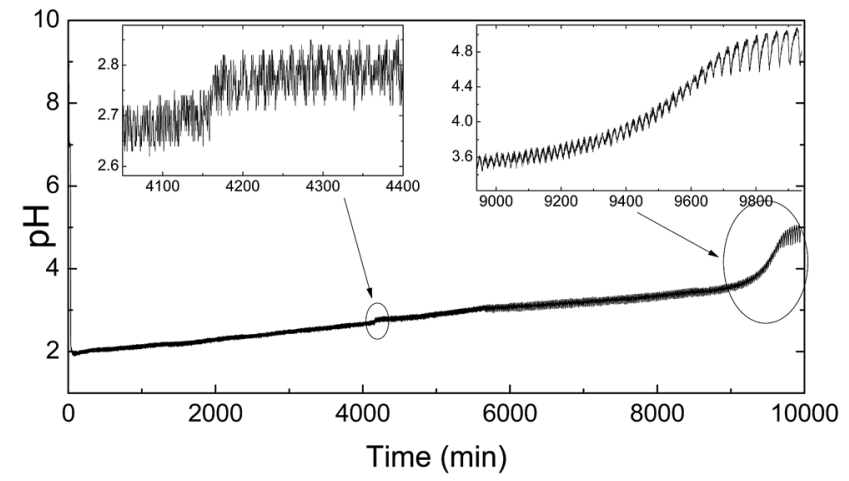

Fig. 4 Oscillations in $\mathrm{pH}$ recorded in $\mathrm{PCOC}$ of $\mathrm{PhAc}$ in methanol using catalyst L-Cat, after addition of $0.228 \mathrm{mmol}$ of $\mathrm{HI}$ to achieve the $\mathrm{pH}$ range where oscillations normally occurred.

solution two catalytic species, $\mathrm{Na}_{2} \mathrm{PdAc}_{2} \mathrm{Cl}_{2}$ and $\mathrm{K}_{2} \mathrm{PdAc}_{2} \mathrm{I}_{2}$, would become available:

$$
\mathrm{Na}_{2} \mathrm{PdAc}_{2} \mathrm{Cl}_{2}+2 \mathrm{KI} \rightleftarrows \mathrm{K}_{2} \mathrm{PdAc}_{2} \mathrm{I}_{2}+2 \mathrm{NaCl}
$$

As can be seen in Fig. 5a, complex mixed-mode oscillations were indeed recorded. Oscillations resembled two oscillatory patterns overlaying each other: large oscillations with a period of 417-523 min and small oscillations with a period of 10-25 min. The captured oscillations are similar to the phenomena observed when PdAc and P-Cat were used with the addition of HI (Fig. 3a and c, now enlarged in Fig. $5 \mathrm{~b}$ and $\mathrm{c}$ ).

The presence of two catalytic species in the PdAc and P-Cat systems may not be the main/only driver for the existence of multiple subnetworks causing switching between large and small amplitude cycles so we also investigated PCOC employing a mixture of $\mathrm{PdAc}$ and $\mathrm{PdI}_{2}$ (4:1 molar content). No HI was externally added to this system. The total content of catalyst in $\mathrm{mol} \%$ was identical to that in PdAc only reaction $(1.336 \times$ $10^{-3} \mathrm{M}$ ). As can be seen from Fig. 6a, in the mixed catalyst system, oscillations started later (after $1400 \mathrm{~min}$ ) and initially had a small amplitude of $0.4-0.5$ and period of $35( \pm 6) \mathrm{min}$ which rapidly increased in amplitude to $2.4( \pm 0.3)$ and a period of $46( \pm 5) \mathrm{min}$. At approximately $4000 \mathrm{~min}$, the periodic oscillations were terminated by a sudden drop in $\mathrm{pH}$. Following this event, small amplitude "climbing" oscillations developed. The increase in $\mathrm{pH}$ and amplitude over time is a characteristic oscillatory shape in the PCOC reaction employing $\mathrm{PdI}_{2},{ }^{10,12,33}$ although the majority of catalytic species in this reaction was PdAc. While the oscillatory patterns using $\mathrm{PdAc}+\mathrm{PdI}_{2}$ had a less obvious mixed-mode behaviour than in PdAc $+\mathrm{HI}$, it is possible to trace the evolution of an overlaid $\mathrm{PdI}_{2}$-induced pattern. When $\mathrm{PdI}_{2}$ and PdAc were used in a 1:1 ratio, only one series of oscillations was observed before the system consumed all substrate (Fig. 6b) and stopped oscillating. Oscillations started after $1200 \mathrm{~min}$ and kept growing in amplitude until they reached $4.4 \mathrm{pH}$ units (the last $\mathrm{pH}$ fall) while the period also increased from $14 \mathrm{~min}$ to $77 \mathrm{~min}$.

The existence of two catalytic species in PdAc and P-Cat was not straightforward, but since the mixed-mode oscillations 
(a)

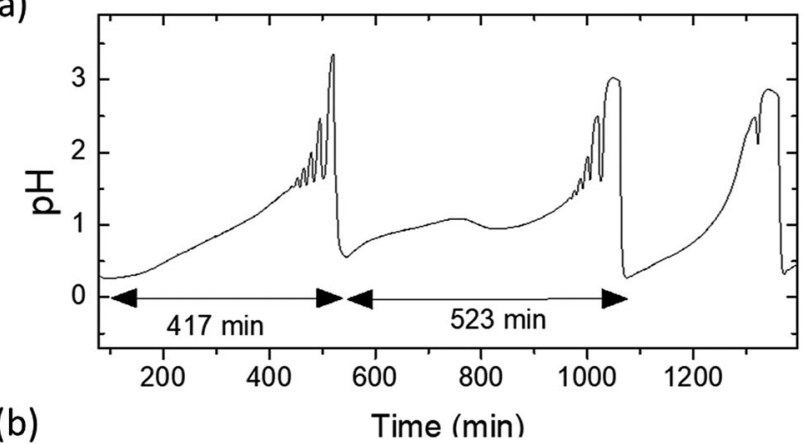

(b)

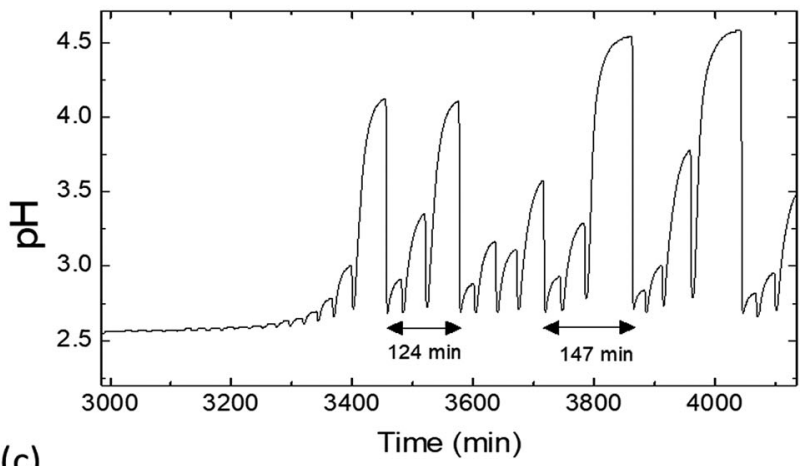

(c)

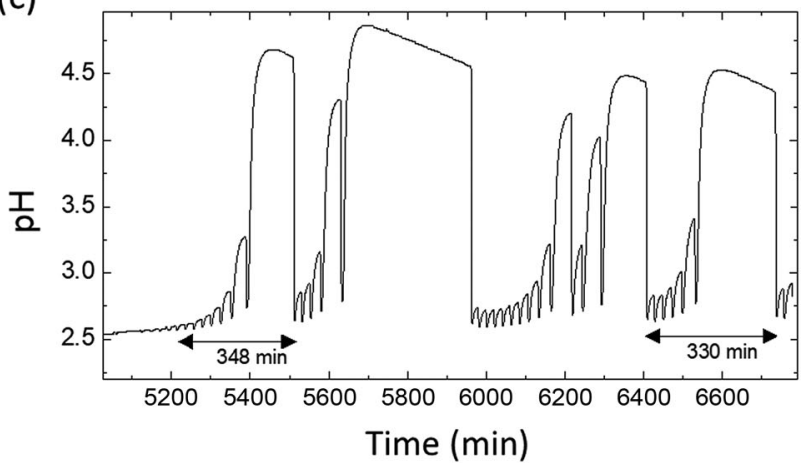

Fig. 5 Enlarged area where mixed-mode oscillations were observed (a) $\mathrm{Na}_{2} \mathrm{PdAc}_{2} \mathrm{Cl}_{2}$; (b) $\mathrm{PdAc}+\mathrm{HI}$ and (c) $\mathrm{P}-\mathrm{Cat}+\mathrm{HI}$.

were observed only after addition of $\mathrm{HI}$, it is possible to suggest that $\mathrm{HI}$ was involved in the generation of $\mathrm{PdI}_{2}$ from a pool of metallic palladium within the pristine catalyst, as follows:

$$
\begin{gathered}
\mathrm{HI}+\mathrm{O}_{2} \rightarrow \mathrm{I}_{2}+\mathrm{H}_{2} \mathrm{O} \\
\mathrm{Pd}^{0}+\mathrm{I}_{2} \rightarrow \mathrm{PdI}_{2} .
\end{gathered}
$$

Generation of additional $\mathrm{PdI}_{2}$ within the reaction mixture would facilitate the existence of two catalysts: $\mathrm{K}_{2} \mathrm{PdAc}_{2} \mathrm{I}_{2}$ and $\mathrm{K}_{2} \mathrm{PdI}_{4}$, one feasible explanation for multiple reaction subnetworks. The presence of metallic palladium in pristine P-Cat and PdAc was confirmed by XPS (Fig. S4, ESI $\dagger$ ). The PdAc catalyst exhibited a double set of Pd $3 d$ 5/2 and 3/2 peaks, indicating that both metallic palladium and $\mathrm{Pd}^{2+}$ were present in the catalyst, with the majority being $\mathrm{Pd}^{2+}$ species. P-Cat only exhibited a set of peaks for $\mathrm{Pd}^{0}$ with a shoulder into higher binding energies, indicating the presence of a smaller concentration of $\mathrm{Pd}^{2+}$ species. The source of metallic palladium
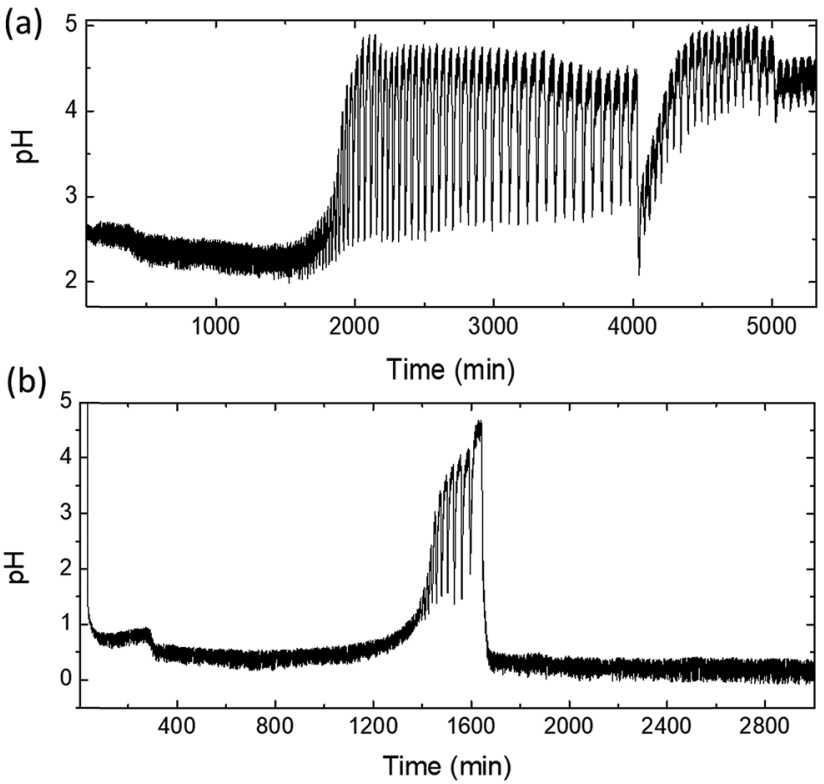

Fig. 6 Oscillations in $\mathrm{pH}$ recorded in $\mathrm{PCOC}$ of $\mathrm{PhAc}$ in methanol using a mixture of $\mathrm{PdAc}$ and $\mathrm{Pdl}_{2} 4: 1 \mathrm{~mol}$ catalysts (a) and $1: 1 \mathrm{~mol}$ catalysts (b),

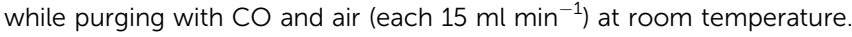

impurities in these commercially available catalysts is unclear. Furthermore, it appeared that due to the absence of metallic palladium in L-Cat (as seen from XPS, Fig. S4, ESI $\dagger$ ), the addition of $\mathrm{HI}$ did not lead to the generation of $\mathrm{PdI}_{2}$ which occurred with PdAc and P-Cat. Therefore, simple periodic oscillations and lack of mixed-mode patterns in this case could be characteristic of a system with a single catalytic species. Further studies involving a longer reaction monitoring time as well as the transition from batch to a CSTR set-up are needed to further understand the observed behaviours.

\section{Starting material conversion and product distribution}

Regarding product generation, both PdAc and P-Cat had a similar product distribution in both HI and non-HI modes with almost 50:50 Z-isomer (5) and DMO (3) and only a trace amount of $E$-isomer (4, see Table 1). In HI mode, however, the product conversion increased significantly from $7.3 \%$ and $3.5 \%$ to $37.4 \%$ and $29.5 \%$ (for PdAc and P-Cat, respectively). Moreover, methyl cinnamate (1), generally considered as an intermediate, was observed in substantial amounts after addition of HI, suggesting that $\mathrm{HI}$ affected the mechanism of the reaction and altered the stoichiometry of the processes.

L-Cat in both modes had a preferential product - $Z$-isomer (5), which was likely to be associated with steric hindrance from bulky triphenylphosphine ligands. Substrate conversion after 4000 min largely depended on the amount of HI added. Thus, after the addition of $0.228 \mathrm{mmol}$ of HI, substrate conversion was $26.9 \%$, which was higher than the conversion when only $0.0228 \mathrm{mmol}$ of $\mathrm{HI}$ was added (14\% at $4600 \mathrm{~min})$ and without any $\mathrm{HI}(9.0 \%$ at $4000 \mathrm{~min})$ (Table 1$)$. This speaks for the ability of $\mathrm{HI}$ to improve the catalytic activity of L-Cat. At the time when conversion was measured (4000 min, Fig. 4) the oscillations 
Table 1 Product distribution (in mol\%) and substrate (PhAc) conversion for various Pd-based catalysts. Product characterisation is discussed in details in ref. 9
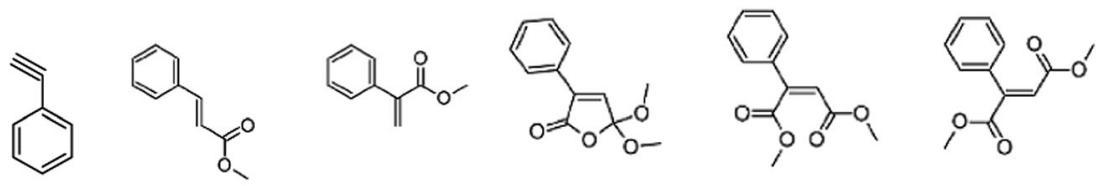

PhAc

1

2

3

4

5

\begin{tabular}{|c|c|c|c|c|c|c|}
\hline mmol & $E$-Isomer (4) & $Z$-Isomer (5) & DMO (3) & MeCin (1) & MeAt (2) & PhAc conversion $(\%)$ \\
\hline PdAc $4000 \mathrm{~min}$ & 0.16 & 3.50 & 3.34 & - & - & 7.3 \\
\hline \multicolumn{7}{|c|}{ After addition of $0.0228 \mathrm{mmol} \mathrm{HI}(1 \times)$} \\
\hline PdAc $5600 \mathrm{~min}$ & 0.45 & 18.34 & 15.15 & 3.43 & 1.19 & 37.4 \\
\hline \multicolumn{7}{|c|}{ After addition of $0.228 \mathrm{mmol} \mathrm{HI}(10 \times)$} \\
\hline L-Cat $4000 \mathrm{~min}$ & 1.03 & 14.00 & 9.79 & 0.18 & 1.91 & 26.9 \\
\hline L-Cat $10000 \mathrm{~min}$ & 3.74 & 16.55 & 9.87 & 0.19 & 1.98 & 32.3 \\
\hline
\end{tabular}

had not started, indicating that the conversion process happened independently of the observable oscillations. Indeed, although the oscillations occurred after $4180 \mathrm{~min}$, the additional conversion of PhAc was only 5.4\% (32.3\% at $10000 \mathrm{~min}$ ), Table 1. This conversion was associated with an increase in formation of $E$ and $Z$-isomers, whereas the concentrations of other products did not change significantly.

\section{Conclusions}

In this report, we demonstrate oscillatory $\mathrm{pH}$ behaviour in systems catalysed by various palladium-based catalysts - from a small molecule palladium acetate to polymer bound phosphineliganded palladium catalyst. While palladium acetate worked along the lines of the previously reported $\mathrm{PdI}_{2}$, giving welldefined highly regular oscillations in the $\mathrm{pH}$ region of $3-4.5 \mathrm{pH}$, the other catalysts only exhibited oscillations after the initial pH drop was forced by addition of hydroiodic acid. Addition of HI not only helped to achieve the oscillations in L-Cat and P-Cat but also dramatically increased phenylacetylene conversion. Moreover, after the addition of HI, PdAc and P-Cat demonstrated mixed-mode oscillations. Further studies are required to identify the reaction subnetworks responsible for the large and small amplitude cycles. However, based on the evidence collected here, it was postulated that the observed complex behaviour was a result of $\mathrm{HI}$ induced conversion of metallic palladium into $\mathrm{PdI}_{2}$ meaning that two competing catalysts, PdAc and $\mathrm{PdI}_{2}$ were present in the system. The overall effect of externally added HI was complex: (i) it decreased the $\mathrm{pH}$ to the range where oscillations in PCOC system are generally observed; (ii) it generated additional $\mathrm{Pd}^{2+}$ from metallic palladium, as observed from XPS; (iii) it led to the observation of complex mixed-mode oscillatory patterns and (iv) it participated in the formation of mono-esters which were typically considered intermediates and not observed among the final products.
This property of highly acidic HI to initiate oscillations when using a catalyst that would not otherwise give rise to oscillations is a promising feature for the targeted $\mathrm{pH}$-mediated drug delivery and release.

\section{Conflicts of interest}

No conflicts of interest to declare.

\section{Acknowledgements}

This work was supported by UK Engineering and Physical Sciences Research Council (EPSRC) grant number EP/N033655/1. X-ray photoelectron spectroscopy (XPS) data were acquired at the National EPSRC XPS Users' Service, an EPSRC Mid-Range Facility. Data supporting this publication is openly available under an 'Open Data Commons Open Database License'. Additional metadata are available at: http://dx.doi.org/10.17634/153345-1. Please contact Newcastle Research Data Service at rdm@ncl.ac.uk for access instructions.

\section{References}

1 A. M. Zhabotinsky, Chaos, 1991, 1, 379-386.

2 A. Isakova and K. Novakovic, Eur. Polym. J., 2017, 95, 430-439.

3 P. Topham, J. R. Howse, C. J. Crook, S. P. Armes, R. A. L. Jones and A. J. Ryan, Macromolecules, 2007, 40, 4393-4395.

4 R. Tamate, A. Mizutani Akimoto and R. Yoshida, Chem. Rec., 2016, 16, 1852-1867.

5 Y. S. Kim, R. Tamate, A. M. Akimoto, R. Yoshida, J. Groen, H. W. H. van Roekel, T. F. A. de Greef, W. T. S. Huck and T. Aida, Mater. Horiz., 2017, 4, 38-54. 
6 Alexander V. Malashkevich, A. Lev, G. Bruk and O. N. Temkin, J. Phys. Chem. A, 1997, 101, 9825-9827.

7 V. R. Khabibulin, A. V. Kulik, I. V. Oshanina, L. G. Bruk, O. N. Temkin, V. M. Nosova, Y. A. Ustynyuk, V. K. Bel'skii, A. I. Stash, K. A. Lysenko and M. Y. Antipin, Kinet. Catal., 2007, 48, 228-244.

8 K. Novakovic, C. Grosjean, S. K. Scott, A. Whiting, M. J. Willis and A. R. Wright, Chem. Phys. Lett., 2007, 435, 142-147.

9 C. Grosjean, K. Novakovic, S. K. Scott, A. Whiting, M. J. Willis and A. R. Wright, J. Mol. Catal. A: Chem., 2008, 284, 33-39.

10 K. Novakovic, A. Mukherjee, M. Willis, A. Wright, S. Scott and A. R. Wright, Phys. Chem. Chem. Phys., 2009, 11, 9044.

11 J. Parker and K. Novakovic, React. Kinet., Mech. Catal., 2016, 118, 73-85.

12 J. Parker and K. Novakovic, React. Kinet., Mech. Catal., 2018, 123, 113-124.

13 L. Donlon and K. Novakovic, Chem. Commun., 2014, 50, 15506-15508.

14 J. Parker and K. Novakovic, ChemPhysChem, 2017, 18, 1981-1986. 15 S. N. Gorodsky, Org. Chem. Int., 2012, 1-6.

16 S. N. Gorodsky, Kinet. Catal., 2012, 53, 493-496.

17 S. N. Gorodsky, React. Kinet., Mech. Catal., 2018, 1-20.

18 Y. Sakurai, S. Sakaguchi and Y. Ishii, Tetrahedron Lett., 1999, 40, 1701-1704.

19 R. F. Heck, J. Am. Chem. Soc., 1972, 94, 2712-2716.

20 S. P. Porras and E. Kenndler, J. Chromatogr. A, 2004, 1037, 455-465.
21 B. Gabriele, L. Veltri, G. Salerno, M. Costa and G. P. Chiusoli, Eur. J. Org. Chem., 2003, 1722-1728.

22 S. N. Gorodskii, A. N. Zakharov, A. V. Kulik, L. G. Bruk and O. N. Temkin, Kinet. Catal., 2001, 42, 251-263.

23 V. N. Zudin, V. D. Chinakov, V. M. Nekipelov, V. A. Rogov, V. A. Likholobov and Y. I. Yermakov, J. Mol. Catal., 1989, 52, 27-48.

24 G. Rabai, M. Orban and I. R. Epstein, Acc. Chem. Res., 1990, 23, 258-263.

25 T. G. Szántó and G. Rábai, J. Phys. Chem. A, 2005, 109, 5398-5402.

26 G. Rábai and I. Hanazaki, J. Phys. Chem. A, 1999, 103, 7268-7273.

27 E. C. Edblom, M. Orban and I. R. Epstein, J. Am. Chem. Soc., 1986, 108, 2826-2830.

28 M. J. B. Hauser, A. Strich, R. Bakos, Z. Nagy-Ungvarai and S. C. Müller, Faraday Discuss., 2002, 120, 229-236.

29 Ž. D. Čupić, L. Z. Kolar-Anić, S. R. Anić, S. R. Maćešić, J. P. Maksimović, M. S. Pavlović, M. C. Milenković, I. N. M. Bubanja, E. Greco and S. D. Furrow, Helv. Chim. Acta, 2014, 97, 321-333.

30 I. N. Bubanja, S. Maćešić, A. Ivanović-Šašić, Ž. Čupić, S. Anić and L. Kolar-Anić, Phys. Chem. Chem. Phys., 2016, 18, 9770-9778.

31 B. D. Aguda, R. Larter and B. L. Clarke, J. Chem. Phys., 1989, 90, 4168-4175.

32 V. Vukojević, S. Anić and L. Kolar-Anić, J. Phys. Chem. A, 2000, 104, 10731-10739.

33 J. Parker and K. Novakovic, Ind. Eng. Chem. Res., 2013, 52, 2520-2527. 